\title{
SCENARIO SIMULATION OF LAND USE/COVER CHANGE IN FUXIAN LAKE BASIN BASED ON CONVERSION OF LAND USE AND ITS EFFECTS AT SMALL REGION EXTENT MODEL, YUNNAN PROVINCE, CHINA
}

\author{
LI, S. H. ${ }^{1}-$ PeNG, S. Y. ${ }^{2 *}-$ JIN, B. X. ${ }^{3}-$ ZHOU, J. S. ${ }^{1}-$ LI, Y. X. ${ }^{2}$ \\ ${ }^{I}$ Yunnan Provincial Geomatics Centre, Kunming 650034, China \\ ${ }^{2}$ College of Tourism \& Geographic Sciences, Yunnan Normal University \\ Kunming 650500, China \\ ${ }^{3}$ Information Center, Department of Natural Resources of Yunnan Province \\ Kunming 650224, China \\ ${ }^{*}$ Corresponding author \\ e-mail: frankmei@126.com; phone: +86-13-888-907-693 \\ (Received $18^{\text {th }}$ Mar 2019; accepted $17^{\text {th }}$ May 2019)
}

\begin{abstract}
The construction of land use change model is an important means to deeply understand the cause and process of land use change, forecast the future development trend and analyze its environmental influence. In order to reveal the evolution law of the basin Land Use/Cover Change (LUCC) under the changing situation, based on Conversion of Land Use and its Effects at Small Region Extent model (CLUE-S), two scenarios of natural growth and ecological protection are set up with Fuxian Lake located in Yunnan province, China, as the research area to simulate the LUCC of the basin in 2020. The results show that the CLUE-S model has high reliability to simulate the future Land Use/Land Cover (LULC) change in the basin scale and the high simulation accuracy as a whole, and the Kappa coefficient is all above 0.8 ; under the scenario of natural change, the ecological lands like forest land, cultivated land, grassland and garden land are decreasing, in which the decrease of forest land is the largest, while the non-ecological lands such as construction piling, building area, structure and road is increasing, and the increase of construction piling is the largest. It is bound to pose a serious threat to the ecological security of the basin; under the scenario of ecological protection, the increase of forest land and water area is the largest, while the cultivated land, grassland, construction piling and garden land are greatly reduced. It shows that the quantity of ecological land increases obviously while the quantity of construction land, planting land and other land which play a restriction on ecological environment protection is decreasing, which will be beneficial to the ecological environment protection of the river basin.
\end{abstract}

Keywords: Fuxian Lake basin, CLUE-S, LUCC, scenario simulation, high-altitude plateau lake ecosystem, LULC conversion rules

\section{Introduction}

LULC changes can have a direct or indirect impact on a variety of eco-environmental factors, thus affecting regional and global sustainable development. The study of its dynamic changes is an important subject of global and regional environmental change (Li, 1996; Wijesekara et al., 2012). Analyzing the change characteristics of LULC, revealing the evolution of different space-time scales and predicting future changes are helpful to reveal the process and mechanism of regional ecological environment change under the influence of human society, and thus provide decision-making basis for regional ecological protection and sustainable development.

At present, the main models of LULC change and simulation in academic circles include system dynamics model, CLUE-S model, multi-agent model, Markov model, 
CA-markov, FLUS model and so on (Bai, 2000; Duan et al., 2004; Hou et al., 2004; Chu et al., 2005; Liu et al., 2006; Qin et al., 2009; Li et al., 2015; Liu et al., 2017; Hu and Zhang, 2018; Wang et al., 2019). Each model has its own advantages and disadvantages, and the CLUE-S model has obvious advantages in reflecting the gradation, relevance and competitiveness of the LULC change space and is unique in the simulation and optimization of LULC change under policy control (Verburg et al., 2002), thus being widely used in the study of LULC change simulation Cities and urban agglomerations (Peng et al., 2007; Li et al., 2009; Guo et al., 2012; Huang et al., 2012; Liu et al., 2012; Feng et al., 2013; Zhang et al., 2013; Wang et al., 2014; Huang et al., 2015; Jiang et al., 2015; Lu et al., 2015; Xu et al., 2016; Li et al., 2017; Liu et al., 2017; Tian et al., 2019), China's rapid economic growth region (Cai et al., 2004; Tan et al., 2006; Sheng et al., 2008; Lu et al., 2009; Wang et al., 2009; Zhang et al., 2011; Zheng et al., 2014; Han et al., 2015), big city fringe area (Meng et al., 2010), inland arid zone (Zhang et al., 2004; Dai et al., 2013), mountainous area (Peng et al., 2007; Zhu et al., 2010; Gao et al., 2013; Zhao et al., 2014), watershed and lake zone (Bai et al., 2005; Wang et al., 2014; Guo et al., 2016; Li et al., 2016; Sun et al., 2016; Bian et al., 2017; Zhu et al., 2019) village and town (Zhu et al., 2010) and forest park (Li et al., 2016) and so on.

Fuxian Lake is a unique low-latitude and high-altitude plateau lake ecosystem in the world. It is an important international lake to study the mechanism of biodiversity formation. Affected by the East Asian and Southwest monsoon, it is the most sensitive representative lake in response to global change. Favored by experts and scholars at home and abroad, it has become one of the hot spots of the research on international lakes, and it is also one of the plateau lake basin systems with the research value of the most ecological fragile areas in geosciences of China. For this reason, this study takes Fuxian Lake Basin as an example and uses CLUE-S model to carry out LUCC simulation research under different scenarios, so as to reveal the characteristics of land use change with high precision and long time series in plateau lake basin, which has the research value of the most ecological fragile area in the field of geosciences in China. The objective of this study is that the impact and effect of quantification and spatial scales of human decision-making factors on the clue-s model. It is of great significance to study the global change response and biodiversity formation mechanism of the unique low-latitude and high-altitude plateau lake ecosystem in the world. At the same time, it provides guidance for how to effectively implement the land use planning, water source protection, ecological restoration and others of Fuxian Lake basin so as to improve the water environment quality of the river basin.

\section{Materials and Methods}

\section{General situation of the study region}

Located in the center of the Central Yunnan Basin, Yuxi City, central Yunnan Province, Fuxian Lake is China's largest deep-water freshwater lake, the first large lake in the source of the Pearl River, and is the Nanpanjiang River system. Its geographical location is $24^{\circ} 21^{\prime} 28^{\prime \prime}-24^{\circ} 38^{\prime} 00^{\prime \prime} \mathrm{N}$ and $102^{\circ} 49^{\prime} 12^{\prime \prime}-102^{\circ} 57^{\prime} 26^{\prime \prime} \mathrm{E}$ (Fig. 1). As one of the nine plateau lakes in Yunnan Province, Fuxian Lake is the second deep-water lake explored in China and the lake area and water storage amount to the 8th and 3rd in China, respectively (Wang et al., 1998). Because of the particularity of its geographical location and its powerful water supply capacity and recreational value, it is known as 
the "plateau pearl" in central Yunnan, serving as an important resource guarantee for the sustainable social and economic development in central Yunnan, the strategic water resource for the regional development of the Pan-Pearl River Delta, as well as the important strategic source of drinking water in the Pearl River Basin and Southwest China (Gao et al., 2013). The water quality of Fuxian Lake is Class I, and is one of the best natural lakes in China.

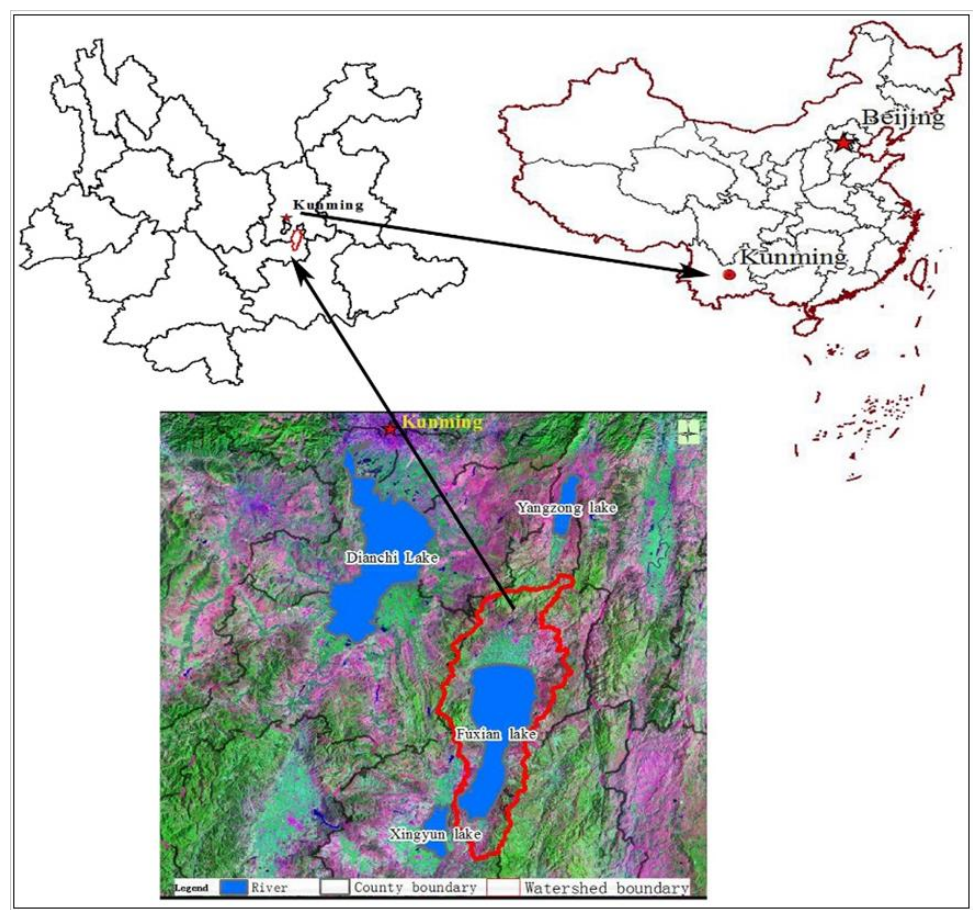

Figure 1. Location of Fuxian lake watershed

The vegetation in the basin is mainly secondary vegetation such as grass, shrub and coniferous forest. The population reaches about 160,300, the rural economy mainly comes from crop production, the main food crops include rice, corn, wheat and so on, and economic crops include flue-cured tobacco and rape. The industry is dominated by phosphorus chemical industry, building materials, food processing and aquatic products, of which phosphorus chemical industry is the pillar industry of this area. The land use type of Fuxian Lake Basin has always been dominated by forests and water areas, but with the improvement of the urbanization level of the basin, human activities have increased disturbance on the natural environment, such phenomena as reclamation of lakes, deforestation, over-exploitation of tourism resources, and the rapid increase of functional buildings result in significant change in land coverage types in Fuxian Lake Basin.

\section{Data sources}

Because of the obvious seasonal variation of rainfall in Fuxian Lake Basin and the large variation of lake area with season, the remote sensing images of relatively stable lake water level during the dry season from January to March are selected, including 5 phases of high spatial resolution remote sensing image data (Table 1, Fig. 2). The reference data are listed in Table 2. 
Table 1. Satellite images

\begin{tabular}{c|c|c|c}
\hline Sensor & Acquired Date & Spatial Resolution & Source \\
\hline QuickBird & $2008-12-18$ & $0.61 \mathrm{~m}$ & Purchased from remote sensing image agents \\
WorldView-2 & $2011-01-29$ & $0.5 \mathrm{~m}$ & Purchased from remote sensing image agents \\
WorldView-2 & $2014-01-26$ & $0.5 \mathrm{~m}$ & Purchased from remote sensing image agents \\
WorldView-2 & $2017-03-28$ & $0.5 \mathrm{~m}$ & Purchased from remote sensing image agents \\
\hline
\end{tabular}
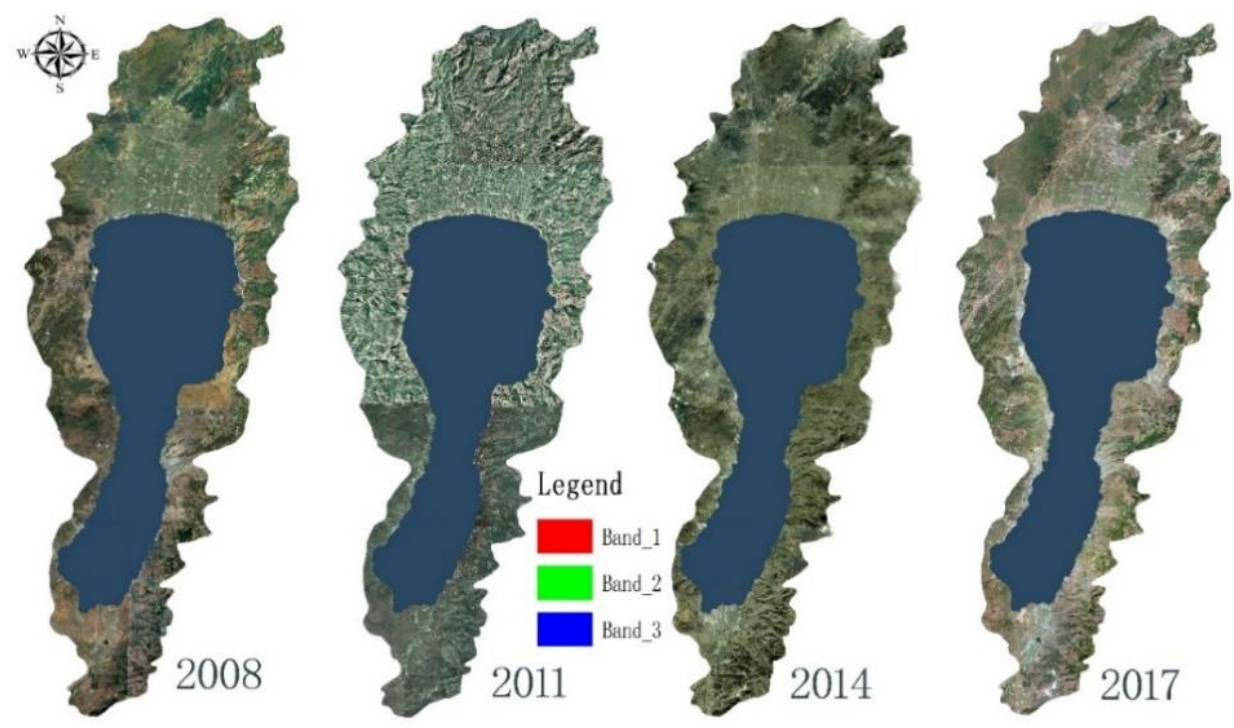

Figure 2. Remote sensing images in study area

Table 2. Supplementary data

\begin{tabular}{|c|c|c|}
\hline Name & Property and Role & Source \\
\hline $\begin{array}{l}\text { Digital Line Graphic } \\
\text { (DLG) }\end{array}$ & $\begin{array}{c}\text { The scale is } 1: 10000 \text {, including road, river, et al. The reference data } \\
\text { sources of orthorectified remote sensing image and Map making of } \\
\text { LULC change driving factors }\end{array}$ & $\begin{array}{l}\text { Yunnan Provincial Bureau } \\
\text { of Surveying and Mapping }\end{array}$ \\
\hline $\begin{array}{l}\text { Digital Orthophoto } \\
\text { Map (DOM) }\end{array}$ & $\begin{array}{l}0.5 \mathrm{~m} \text { resolution, acquire date } 2014 \text {. The reference data sources of } \\
\text { orthorectified remote sensing image }\end{array}$ & $\begin{array}{l}\text { Yunnan Provincial Bureau } \\
\text { of Surveying and Mapping }\end{array}$ \\
\hline $\begin{array}{l}\text { Digital Elevation } \\
\text { Model (DEM) }\end{array}$ & $\begin{array}{c}10 \mathrm{~m} \text { grid spacing. The reference data sources of orthorectified } \\
\text { remote sensing image and the basin's boundary extracted, elevation, } \\
\text { slope and slope direction are derived from DEM }\end{array}$ & $\begin{array}{l}\text { Yunnan Provincial Bureau } \\
\text { of Surveying and Mapping }\end{array}$ \\
\hline $\begin{array}{l}\text { GPS and triangle } \\
\text { points }\end{array}$ & $\begin{array}{c}\text { GPS C-level points and triangle points of each level measured from } \\
1985 \text { to 2013. The reference data sources of orthorectified remote } \\
\text { sensing image }\end{array}$ & $\begin{array}{l}\text { Yunnan Provincial Bureau } \\
\text { of Surveying and Mapping }\end{array}$ \\
\hline $\begin{array}{l}\text { Land use/ Land } \\
\text { cover }\end{array}$ & $\begin{array}{c}\text { The product of the first national geographical situation survey in } \\
\text { Yunnan Province. The training data and test data for LULC } \\
\text { extraction from remote sensing image. }\end{array}$ & $\begin{array}{l}\text { Yunnan Provincial Bureau } \\
\text { of Surveying and Mapping }\end{array}$ \\
\hline Driving factors & $\begin{array}{l}\text { Precipitation, Temperature, population density, GDP of primary } \\
\text { Industry, GDP of secondary industry, GDP of tertiary industry. }\end{array}$ & $\begin{array}{l}\text { Statistical Yearbook of } \\
\text { Yuxi City }(2008,2011 \\
\text { 2014, 2017) }\end{array}$ \\
\hline Driving factors & $\begin{array}{l}\text { soil moisture content . The product of the National Geographical } \\
\text { state monitoring demonstrative project -Dynamic monitoring for } \\
\text { ecological environment in Fuxian lake watershed }\end{array}$ & $\begin{array}{l}\text { Yunnan Provincial Bureau } \\
\text { of Surveying and Mapping }\end{array}$ \\
\hline Restricted factors & $\begin{array}{l}\text { The vector of Fuxian Lake Basin Planning is restricted spatial area } \\
\text { of watershed. The 13th Five-Year Plan of Fuxian Lake Basin (2016- } \\
\text { 2020), which is reference of Scenario construction. }\end{array}$ & $\begin{array}{l}\text { Fuxian Lake } \\
\text { Administration Bureau of } \\
\text { Yuxi City }\end{array}$ \\
\hline
\end{tabular}




\section{Analysis methods}

\section{LULC information extraction}

The first-class classification system (water area, desert and bare surface, cultivated land, structure, garden land, grassland, forest land, house building, road and construction land) in the general survey contents and indicators of geographical conditions (GDPJ 01-2013) is adopted as a classification system for extracting LULC information of this remote sensing image, and the definition of each type is shown in GDPJ 01-2013. Due to the difference of remote sensing image data sources and time phase, training samples and test samples are collected from the remote sensing images in 2008, 2011, 2014 and 2017, respectively. For each LULC type of images in each phase, 2000 samples are collected, 70\% of which are used for training samples and 30\% for test samples. The MSORF method (refer to the Reference (Li, 2018) for details) is used to obtain the LULC classification results of the river basin in 2008, 2011, 2014 and 2017. The classification accuracy Kappa is generally 0.8 or more, i.e., 2008 (0.812), 2011 (0.819), 2014 (0.822), and 2017 (0.805). Referring to the current land use map and remote sensing images, the classified data are manually modified to form the final LULC information (Fig. 3).

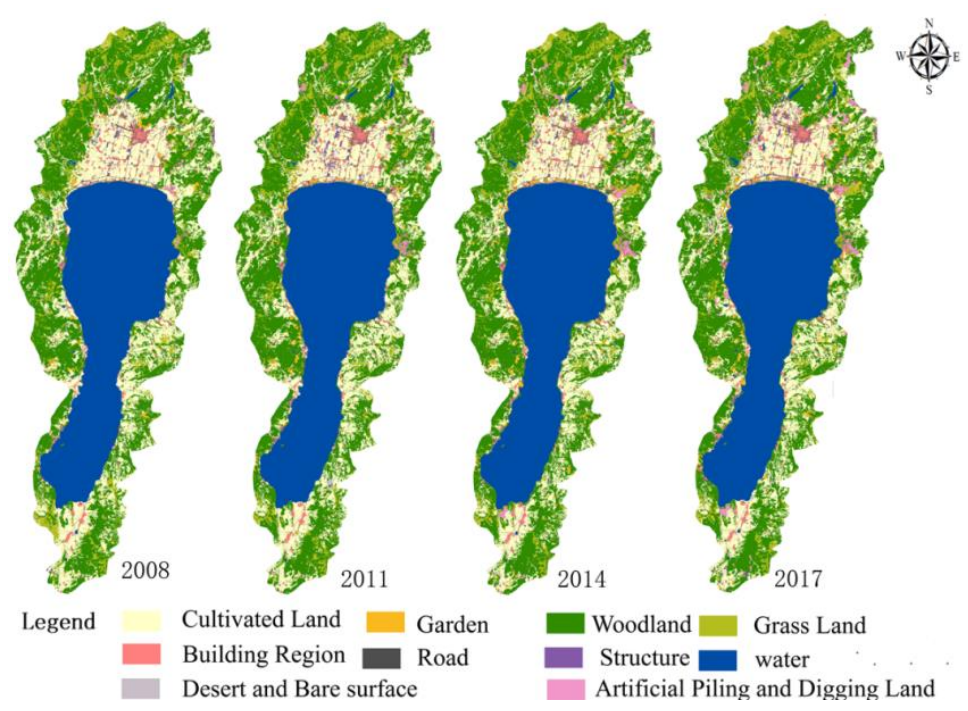

Figure 3. Classification result of LULC in study area

In the ArcGIS platform, the LULC classification results were statistically analyzed, and the area change rate of each land type during the study period was obtained to reflect the temporal change characteristics of the LULC (Table 3).

Table 3 shows that in 2008-2017, water (W), woodland (WL), cultivated land (CL) and grass land (GL) are the four main types of surface cover. The total area of these four types is $95.00 \%, 93.89 \%, 93.43 \%$ and $92.50 \%$ in 2008, 2011, 2014, 2017, respectively, and Building Region (BR), road (R), garden $(\mathrm{G})$, structure $(\mathrm{S})$, Artificial Piling and Digging Land (APDL), Desert and Bare surface (DB) is 5.00\%, 6.11\%, $6.57 \%$ and $7.50 \%$. The results indicate the area of artificial surface types has increased over years, while that of the natural surface cover types is opposite. The area of artificial excavation land in 2017 is four times of that in 2008. The area of water only decreased $0.03 \%$ from 2008 to 2017. 
Due to the socio-economic development of the basin and the enhancement of human activities, the LULC type closely related to human economic activities shows a strong growth momentum. Since 2006, due to the implementation of the policy of returning CL to WL and GL, the CL has shown a decreasing trend, and the area of WL has decreased first and then increased. While GL changes little. The main reason is due to natural succession, returning CL to GL, artificial sowing, etc. The area of DB has been changing from increase to decline year by year. The water area remains basically unchanged.

Table 3. LULC Types Statistics in Fuxian Lake Basin from 2008 to 2017 (area $\left(\mathrm{hm}^{2}\right)$, percent (\%))

\begin{tabular}{c|c|c|c|c|c|c|c|c}
\hline Year & \multicolumn{2}{|c|}{$\mathbf{2 0 0 8}$} & \multicolumn{2}{c|}{$\mathbf{2 0 1 1}$} & \multicolumn{2}{c}{$\mathbf{2 0 1 4}$} & \multicolumn{2}{c}{$\mathbf{2 0 1 7}$} \\
LULC type & Area & Percent & Area & Percent & Area & Percent & Area & Percent \\
\hline CL & 15355.33 & 22.74 & 14391.91 & 21.31 & 13840.46 & 20.49 & 13650.52 & 20.21 \\
G & 496.4 & 0.74 & 783.78 & 1.16 & 973.87 & 1.44 & 958.98 & 1.42 \\
WL & 21947.51 & 32.50 & 22596.69 & 33.46 & 22472.71 & 33.28 & 22029.85 & 32.62 \\
GL & 4924.57 & 7.29 & 4643.56 & 6.88 & 4940.17 & 7.32 & 4880.06 & 7.23 \\
BR & 1368.26 & 2.03 & 1465.69 & 2.17 & 1486.01 & 2.20 & 1608.54 & 2.38 \\
R & 674.57 & 1.00 & 732.43 & 1.08 & 732.93 & 1.09 & 801.09 & 1.19 \\
S & 424.57 & 0.63 & 591.36 & 0.88 & 443.08 & 0.66 & 563.83 & 0.83 \\
APDL & 288.87 & 0.43 & 412.46 & 0.61 & 703.49 & 1.04 & 1017.89 & 1.51 \\
DB & 127.03 & 0.19 & 142.81 & 0.21 & 100.25 & 0.15 & 115.02 & 0.17 \\
W & 21925.16 & 32.47 & 21771.58 & 32.24 & 21839.30 & 32.34 & 21906.48 & 32.44 \\
\hline Total
\end{tabular}

\section{Simulation method of LULC change scenarios in the basin}

The CLUE-S model (the conversion of land use and its effects at small regional extent) is the improved CLUE model by Verburg et al. (2002). It is a dynamic and small-scale spatial distribution simulation model of LULC change. Its model framework is composed of spatial allocation model and non-spatial demand module. Non-spatial demand module, based on natural and socio-economic analysis, predicts the annual LULC-type demand area of the study region in the future. However, the spatial allocation model is driven by the LULC demand, based on the rasterized spatial data, and allocate the demand change of the annual LULC type according to the LULC conversion rules and the LULC spatial distribution probability, so as to realize the spatial simulation of LULC change. See the CLUE-S operating manual (Verburg and Overmars, 2009; Verburg et al., 2002) for a detailed description.

\section{Scenario construction of LULC change in the basin}

The determination of LULC changing situation is based on the rational thought of "if," and "then". If the set conditions are met, what will happen to the future LULC. Therefore, according to relevant policies and development plans such as the Regulations on the Protection of Fuxian Lake in Yunnan Province (implemented on September 29, 2016), and the Protection and Development Plan for Fuxian Lake Basin (2016-2020), and the Overall Land Use Planning of Fuxian Lake Basin, two scenarios such as "natural change" and "ecological protection" are set to simulate the LULC change of Fuxian Lake Basin in 2020.

The natural change scenario is based on the actual number of LULC changes in the Fuxian Lake Basin from 2008 to 2017, assuming that the LULC changes in the Fuxian 
Lake Basin are not substantially affected by policy regulation and external policies, and mainly considering the relationship between the natural and socio-economic development indicators and LULC changes, changing with the change rate from 2008 to 2017.

The ecological protection scenario is mainly set according to the contents of the ecological environmental protection planning of the river basin, and the special location and number of ecological lands (water area, forest land, cultivated land and grassland) within the river basin will be adjusted according to the designated and strict requirements of the ecological protection red line. The specific assumption is that the construction land is correspondingly reduced, the water area remains unchanged, the forest land continues to increase, and the forest coverage rate is more than $35 \%$ (about 236 square kilometers).

\section{Scenario simulation of LULC changes in the basin based on CLUE-S model}

Referring to the CLUE-S model manual and relevant cases and documents, according to the set scenario, the steps of using the CLUE-S model to simulate the LULC change of the basin include the calculation of regression coefficient and land demand, restriction area setting, LULC change driving factor analysis, change matrix setting and other main steps. In order to ensure the reliability and accuracy of the simulation results, the file formed in the above steps must be subject to uniform coordinate and scale, mask, format conversion, etc. before being input into the model, so that the data has a consistent reference system and number of rows and columns, the same coordinate origin and uniform ASCII data format.

(1) Calculation of regression coefficient. The regression parameter file is a file in which the CLUE-S model records the correlation size between each land type and the driving factor calculated by logistic regression analysis. Before calculating the regression coefficient, it is necessary to define the main driving factors of LULC change of the basin. In consideration of the availability and quantification of the data, factors such as the distance from the nearest township center, the distance from the nearest river, the distance from the nearest road, elevation, slope, slope direction, annual average rainfall, annual average temperature, population density, the output value of tertiary industry and soil water content are selected as the driving factors of LULC change of the basin. By means of collinearity analysis, it is found that there is no collinearity among the selected 11 driving factors, and the collinearity coefficient is all less than 0.02 , which meets the requirement of model collinearity.

(2) Land use demand in the scenario of basin change. According to the set natural change and ecological protection scenario, combined with the characteristics of CLUE$\mathrm{S}$ model, the demand of LULC type quantity is taken as scenario assumption condition, and input into the model to analyze its influence on the spatial distribution of LULC of the basin. Among them, the cultivated land area, water area and total grain output of the river basin are used as LULC demand files, and the missing year data are supplemented with linear interpolation method. The 2017 simulation of the 2020 demand is based in part on data from previous years using the GM $(1,1)$ model in the DPS. The land use demand for each year are shown in Table 4.

In the Table 4, Cultivated Land (CL), Woodland (WL), Garden (G), Grass Land (GL), Building Region (BR), Road (R), Structure (S), Artificial Piling and Digging Land (APDL), Water (W), Desert and Bare surface (DB). The bellows is the same. 
Table 4. Land use needs under natural growth and ecological protection scenarios in the Fuxian Lake Basin from 2014 to $2020\left(\mathrm{hm}^{2}\right)$

\begin{tabular}{c|c|c|c|c|c|c|c|c|c|c}
\hline \multirow{2}{*}{$\begin{array}{c}\text { year } \\
\text { LULC type }\end{array}$} & $\mathbf{2 0 0 8}$ & $\mathbf{2 0 1 1}$ & $\mathbf{2 0 1 4}$ & $\mathbf{2 0 1 7}$ & \multicolumn{2}{|c|}{$\mathbf{2 0 1 8}$} & \multicolumn{2}{|c|}{$\mathbf{2 0 1 9}$} & \multicolumn{2}{|c|}{$\mathbf{2 0 2 0}$} \\
\cline { 6 - 10 } & & & & & $\begin{array}{c}\text { Natural } \\
\text { growth }\end{array}$ & $\begin{array}{l}\text { Ecological } \\
\text { protection }\end{array}$ & $\begin{array}{c}\text { Natural } \\
\text { growth }\end{array}$ & $\begin{array}{c}\text { Ecological } \\
\text { protection }\end{array}$ & $\begin{array}{c}\text { Natural } \\
\text { growth }\end{array}$ & $\begin{array}{c}\text { Ecological } \\
\text { protection }\end{array}$ \\
\hline CL & 15355.33 & 14391.91 & 13840.46 & 13650.52 & 13587.21 & 11547.04 & 13523.89 & 9443.56 & 13460.58 & 7340.08 \\
G & 496.4 & 783.78 & 973.87 & 958.98 & 954.02 & 793.63 & 949.05 & 628.27 & 944.09 & 462.92 \\
WL & 21947.51 & 22596.69 & 22472.71 & 22029.85 & 21882.23 & 25379.13 & 21734.61 & 28728.42 & 21586.99 & 32077.7 \\
GL & 4924.57 & 4643.56 & 4940.17 & 4880.06 & 4860.02 & 4224.08 & 4839.99 & 3568.11 & 4819.95 & 2912.13 \\
BR & 1368.26 & 1465.69 & 1486.01 & 1608.54 & 1649.39 & 1562.34 & 1690.24 & 1516.13 & 1731.09 & 1469.92 \\
R & 674.57 & 732.43 & 732.93 & 801.09 & 823.82 & 782.72 & 846.53 & 764.36 & 869.25 & 745.99 \\
S & 424.57 & 591.36 & 443.08 & 563.83 & 604.08 & 520.73 & 644.33 & 477.63 & 684.58 & 434.53 \\
APDL & 288.87 & 412.46 & 703.49 & 1017.89 & 1122.69 & 678.59 & 1227.49 & 339.30 & 1332.29 & 0 \\
DB & 127.03 & 142.81 & 100.25 & 115.02 & 119.94 & 76.68 & 124.87 & 38.34 & 129.79 & 0 \\
W & 21925.16 & 21771.58 & 21839.30 & 21906.48 & 21928.87 & 21967.32 & 21951.27 & 22028.16 & 21973.66 & 22089 \\
\hline Total
\end{tabular}

(3) Restricted area file setting. The spatially restricted area mainly refers to all kinds of planning areas demarcated by government departments, such as land use planning data, ecological environment protection red line and other planning limitation areas of the basin. In the simulation process, the restricted area will not be changed once being set and directly affects the whole simulation process. The restricted area of this study is mainly the basic farmland protection area in the basin, and the red line area of basin ecological protection in the 13th Five-Year Plan (2016-2020) of water environmental protection in Fuxian Lake Basin (Fig. 4).

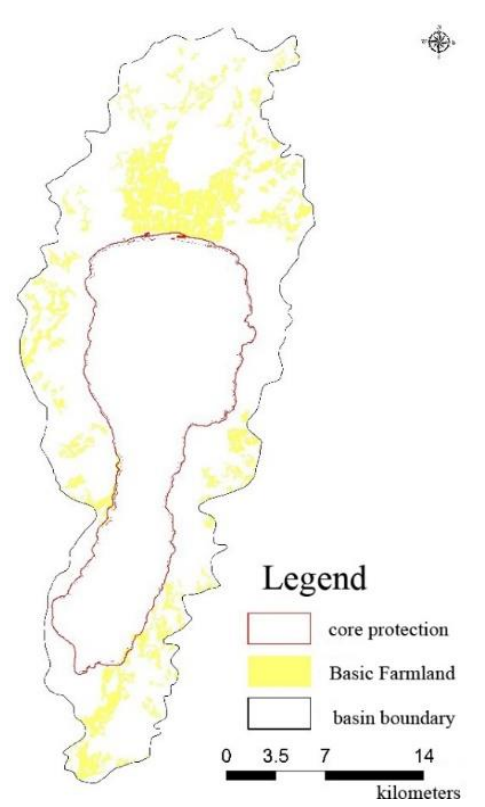

Figure 4. The restricted spatial area of watershed LULC change simulation under different scenarios

This file is the restricted area file of the model, but the land use status map is reclassified before the model is input and the value of LULC type must start from 0; the restricted area file is binarized by re-classifying in the same way, that's, water area (0), 
forest land (1), building area (2), garden land (3), cultivated land (4), grassland (5), road (6), structure (7), desert and bare land (8), and construction land (9). In the CLUE-S model, the LULC active area, i.e., the unrestricted area, the value will be set to be "0", while the value of the restricted area vwill be set to be "-9998".

(4) Map making of LULC change driving factors. Using the annual LULC information classification results, the road and river data are extracted, and the distance map of each pixel from the nearest river, township center and road is calculated using grid space analysis; rainfall, temperature, population density and economic vector map is made through ArcGIS vector space analysis function; elevation, slope and slope direction are derived from DEM; the extraction algorithm of soil water content based on image (wave band) was used to extract soil water content and make soil water content map, as shown in Fig. 5.

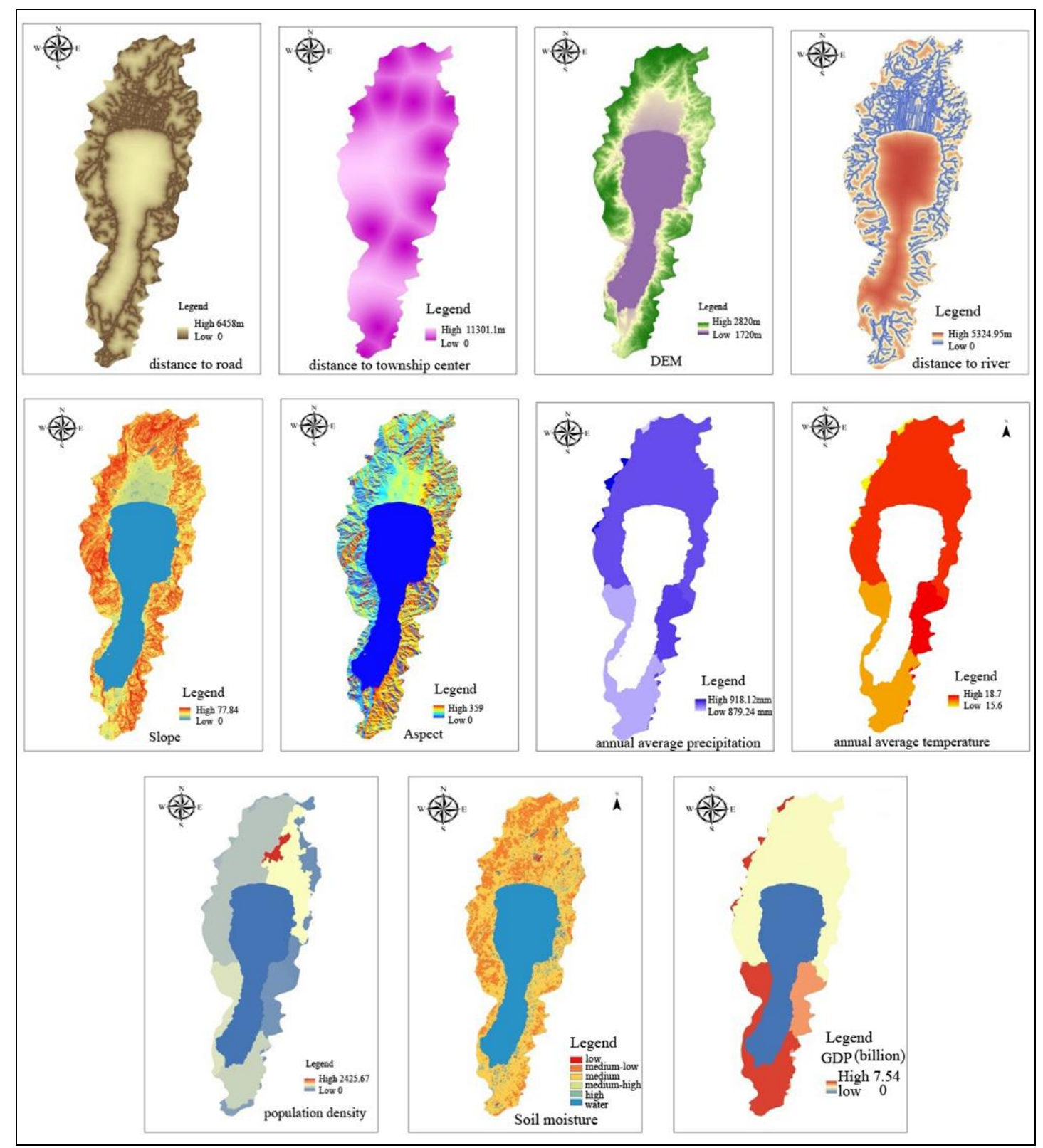

Figure 5. The driver forces map of land use change 
(5) LULC change matrix setting. The LULC transfer matrix refers to the possibility matrix of mutual conversion between different LULC types according to the set scenario during the research period. Thus, the conversion matrix is set to $10 * 10$, the rows representing the period year LULC type, and the columns representing the target year LULC type. If Class A can be conversed to be Class B, it is 1, otherwise it is 0 .

(6) Conversion elasticity settings. Conversion elasticity reflects the difficulty with which each LULC type can be converted to another type. Its value ranges from 0 (easy to convert) to 1 (non-convertible). The closer it is to 1 , the more stable it is, and the more difficult it is to be changed. The magnitude of the conversion elasticity is generally expressed by transition probability matrix. Using the LULC classification result of the basin, the LULC transition probability matrix for 2008-2011, 2011-2014 and 2014-2017 can be calculated. The values on the diagonal represent the stability of this LULC type, i.e. the conversion elasticity (Table 5).

Table 5. LULC conversion elasticity in watershed from 2008 to 2017

\begin{tabular}{c|c|c|c|c}
\hline \multirow{2}{*}{ LULC type } & \multicolumn{3}{|c|}{ conversion elasticity } & \\
\cline { 2 - 5 } & $\mathbf{2 0 0 8} \mathbf{2 0 1 1}$ & $\mathbf{2 0 1 1} \mathbf{2 0 1 4}$ & $\mathbf{2 0 1 4} \mathbf{2 0 1 7}$ & average \\
\hline CL & 0.93 & 0.89 & 0.92 & 0.91 \\
G & 0.89 & 0.64 & 0.90 & 0.81 \\
WL & 0.95 & 0.95 & 0.96 & 0.95 \\
GL & 0.80 & 0.72 & 0.87 & 0.80 \\
BR & 0.98 & 0.96 & 0.98 & 0.97 \\
R & 0.97 & 0.92 & 0.97 & 0.95 \\
S & 0.79 & 0.66 & 0.52 & 0.66 \\
APDL & 0.78 & 0.55 & 0.85 & 0.73 \\
DB & 0.44 & 0.17 & 0.58 & 0.40 \\
W & 0.99 & 0.99 & 0.99 & 0.99 \\
\hline
\end{tabular}

Table 5 shows that in 2008-2017, the conversion elasticity of all land types fluctuates less and has a higher conversion elasticity. Among them, the conversion elasticity between desert and bare land is the lowest, which is only 0.4, indicating that it is difficult to convert to other places, while the conversion elasticity of other lands is above 0.7, and the water area is the most stable. Because there is a certain band of the conversion elasticity value of each type in the three periods, and the setting of the stability parameter has a great influence on the simulation result, the average value of the three periods is used as the stability parameter among different LULC types in the study area.

(7) Determination of the simulation scale of LULC change in the river basin. In the CLUE-S model, the iteration of spatial allocation is a process in which the demand of LULC type in the research area interacts with the natural, social and economic factors in the grid element, and has obvious scale effect. Under the influence of the same driving factors, taking $10 \mathrm{~m}, 30 \mathrm{~m}, 60 \mathrm{~m}$ and $100 \mathrm{~m}$ as the spatial scales of the experiment, the logistic regression analysis models of various spatial scales of each LULC type are constructed, respectively, and the results are described in terms of Area Under Receiver Operating Characteristic (ROC) Curve (AUC) values (Fig. 6); then, the simulation results of each spatial scale are compared with the LULC type result map of the actual year to calculate the Kappa value of the land type. The results show that because there are too many pixels on the $10 \mathrm{~m}$ grid scale and the calculation amount is too large, the 
results cannot be calculated in the Logistic analysis with errors reported and from the AUC curve, the AUC curves at $30 \mathrm{~m}$ scale are above the $60 \mathrm{~m}$ and $100 \mathrm{~m}$ scale curves as a whole. Moreover, the Kappa value and average value of cultivated land, building area, forest land and garden land reach more than 0.9, which is generally higher than other spatial scales, so $30 \mathrm{~m} * 30 \mathrm{~m}$ is chosen as the optimal spatial scale for this simulation.

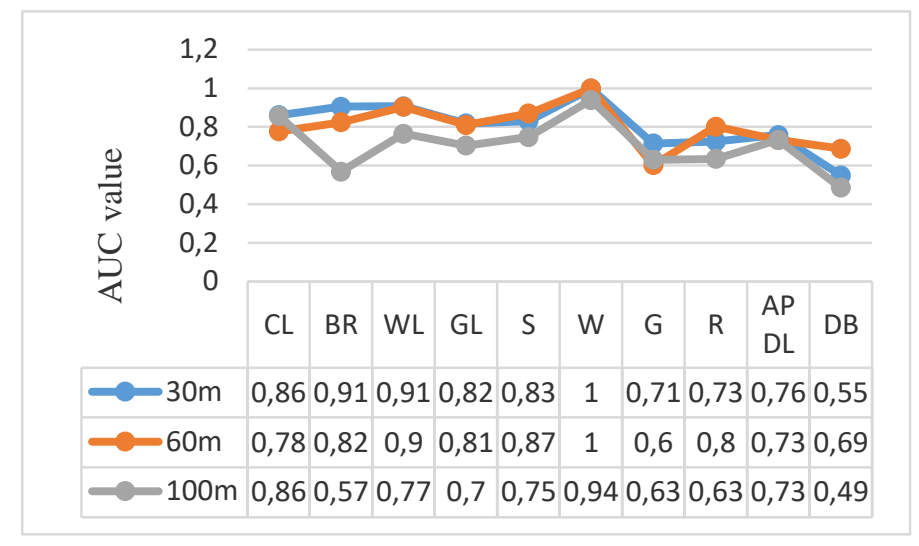

Figure 6. The AUC change of muti-scale LULC simulation in watershed

(8) Simulation of LULC change scenarios in the river basin. Determine the analysis grid size of $30 \mathrm{~m} * 30 \mathrm{~m}$ by using the above-set LULC change simulation parameters, and update the population, rainfall amount, temperature, output value and soil water content by using the selected driving factors with the LULC status chart in 2017 as a reference. According to the set scenario and restriction conditions, the LULC change of Fuxian Lake Basin in 2020 is simulated. The results are shown in Fig. 7.
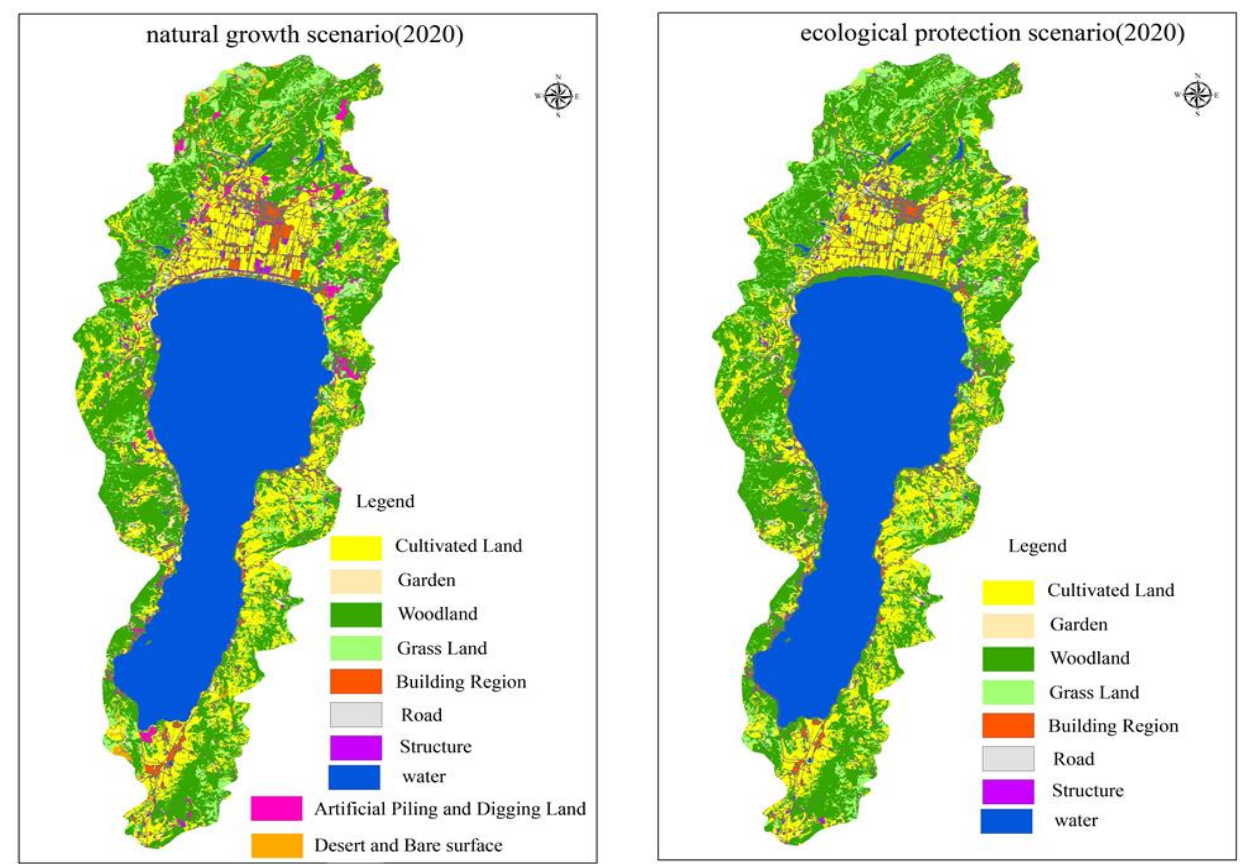

Figure 7. The results of LULC change simulation under different scenarios in Watershed 
(9) Verification of simulation accuracy. Based on the LULC results of Fuxian Lake in 2008, 2011 and 2014, the time duration is three years to simulate the LULC changes in 2011, 2014 and 2017 in three times. After the simulation is completed, the result files cov all. *2011, cov_all. *2014, and cov all. * 2017 are transformed to form a final simulation result (Fig. 8).

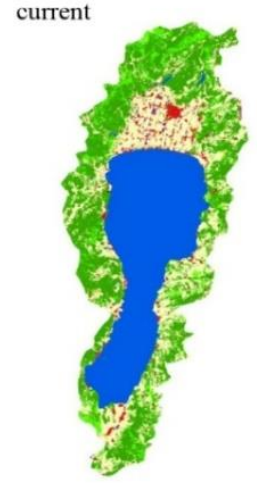

2011

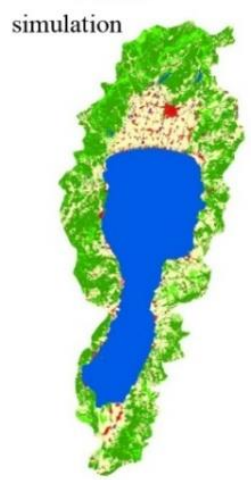

2011

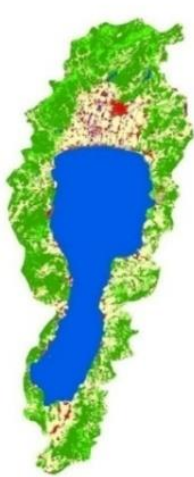

2014

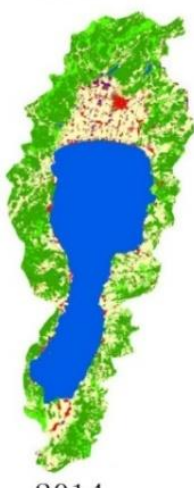

2014

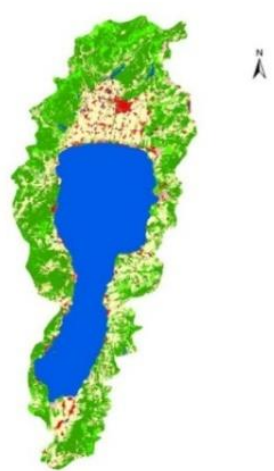

2017

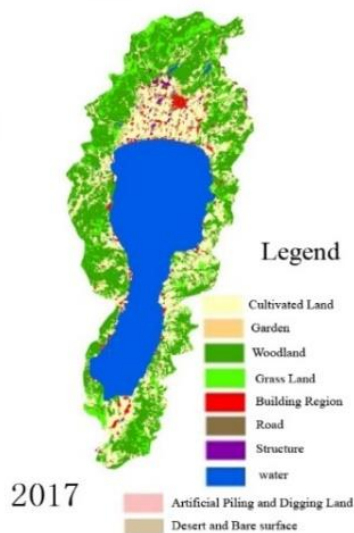

Figure 8. The Comparison of LULC simulation results with current status map

It is the most effective method to evaluate the accuracy of the simulation results by comparing the simulation results with the actual LULC graphs in this year (Verberg, 1999). The AUC value and Kappa coefficient of logistic regression analysis are used to verify the accuracy of the simulation results. The simulation results for 2011, 2014, and 2017 are compared with the actual LULC graph for the year to verify the accuracy of the simulation from both spatial and quantitative variations. From the space intersection analysis, the spatial distribution difference of the simulation precision can be obtained, the grid calculation tool is used to subtract the simulation result from the actual result classification graph, and the correct grid number ( 0 -value grid) can be calculated, to obtain Kappa value (Table 6).

As can be seen from Table 6, the overall simulation accuracy is high, but there is a difference among various land classes. The simulation accuracy of garden land, structure and construction land is relatively low, of which the construction land is the lowest. The Kappa index of the water area and the cultivated land is above 0.9, the water area is above 0.99, which is very high, and the simulation result is almost consistent with the actual result. The results show that the driving factors selected in the study can better explain the spatial change of LULC. Because the garden land, structure, 
construction land, desert and bare land are greatly disturbed by human factors, the simulation effect is not very good.

Table 6. Accuracy verification of simulation result

\begin{tabular}{c|c|c|c|c|c|c}
\hline \multirow{2}{*}{ LULC type } & \multicolumn{3}{|c|}{ Kappa } & \multicolumn{3}{c}{ Raster count } \\
\cline { 2 - 6 } & $\mathbf{2 0 1 1}$ & $\mathbf{2 0 1 4}$ & $\mathbf{2 0 1 7}$ & $\mathbf{2 0 1 1}$ & $\mathbf{2 0 1 4}$ & $\mathbf{2 0 1 7}$ \\
\hline CL & 0.979 & 0.954 & 0.924 & 175542 & 166530 & 164556 \\
G & 0.750 & 0.687 & 0.546 & 4290 & 6253 & 6514 \\
WL & 0.993 & 0.977 & 0.996 & 242170 & 245875 & 248165 \\
GL & 0.984 & 0.941 & 0.970 & 55531 & 54247 & 53388 \\
BR & 0.940 & 0.967 & 0.932 & 14423 & 15819 & 16020 \\
R & 0.957 & 0.908 & 0.892 & 7247 & 7520 & 7520 \\
S & 0.735 & 0.830 & 0.649 & 3586 & 5537 & 5862 \\
APDL & 0.661 & 0.664 & 0.271 & 2216 & 3208 & 3084 \\
DB & 0.936 & 0.774 & 0.858 & 1316 & 1247 & 1145 \\
W & 0.998 & 0.992 & 0.996 & 243982 & 243630 & 243660 \\
\hline
\end{tabular}

\section{Analysis of Results}

\section{The change characteristics of LULC quantity}

The simulation results for 2020 under different scenarios are compared with the 2017 LULC type status chart to analyze the quantitative and spatial changes (Table 7).

Table 7 shows that under the natural change scenario, the forest land, farmland, grassland and garden land show a decreasing trend, and the forest land decrease is the largest, while the construction land, building area, structure and road show an increasing trend, and the increase of the construction land is the largest.

Table 7. Simulation results of LULC type change under different scenario

\begin{tabular}{c|c|c|c|c|c}
\hline $\begin{array}{c}\text { LULC } \\
\text { type }\end{array}$ & $\mathbf{2 0 1 7}$ & $\begin{array}{c}\text { Natural Growth } \\
\mathbf{( 2 0 2 0})\end{array}$ & $\begin{array}{c}\text { Ecological } \\
\text { protection(2020) }\end{array}$ & $\begin{array}{c}\text { Natural Growth } \\
\text { change (2020) }\end{array}$ & $\begin{array}{c}\text { Ecological protection } \\
\text { Change (2020) }\end{array}$ \\
\hline CL & 13650.52 & 13460.58 & 7340.08 & -189.94 & -6310.44 \\
G & 958.98 & 944.09 & 462.92 & -14.89 & -496.06 \\
WL & 22029.85 & 21586.99 & 32077.7 & -442.86 & 10047.85 \\
GL & 4880.06 & 4819.95 & 2912.13 & -60.11 & -1967.93 \\
BR & 1608.55 & 1731.09 & 1469.92 & 122.54 & -138.63 \\
R & 801.09 & 869.25 & 745.99 & 68.16 & -55.1 \\
S & 563.83 & 684.58 & 434.53 & 120.75 & -129.3 \\
APDL & 1017.89 & 1332.29 & 0 & 314.4 & -1017.89 \\
DB & 115.02 & 129.79 & 0 & 14.77 & -115.02 \\
W & 21906.48 & 21973.66 & 22089 & 67.18 & 182.52 \\
\hline
\end{tabular}

According to the spatial distribution of the change, the cultivated land in the village farmland area decrease obviously, while the impervious surface and other land increase, the forest and grass coverage in the phosphate rock area decreases, and other land increases. However, the impervious surface and other land use in the urban area show an increasing trend, while the cultivated land shows a decreasing trend. The numerical and spatial changes of LULC/coverage changes in the basin in natural situation reflect the comprehensive effects of natural and human factors. Along with the improvement of the urbanization level of the river basin, the construction land of the river basin occupies 
a large amount of cultivated land, especially the flat area on the north bank (urban area) of Fuxian Lake is the most prominent, which leads to the larger reduction of highquality cultivated land in the river basin and thus poses a certain threat to the planting level and the safety of grain production in the river basin. At the same time, along with the large increase of other land use in phosphate rock area (desert and bare surface) and impervious surface in urban area promotes surface pollutants to flow into rivers, further aggravating the threat of non-point source pollution to lake-entering rivers, and the forest and grass coverage decreases, which will inevitably pose a serious threat to the ecological security of the river basin.

Under the circumstance of ecological protection, the increase of forest land and water area is the largest, while the cultivated land, grassland, construction land and garden land are greatly reduced. The quantity of ecological land increases obviously, while the quantity of construction land, planting land and other land that restrict the ecological environment protection shows a decreasing trend, which will benefit the ecological environment protection of the river basin. According to the spatial distribution of changes, the other land (desert and bare surface) in the phosphate rock area, the construction land in the urban area, the cultivated land in the village farmland area are greatly reduced, and the forest and grass coverage in the three areas have increased greatly. The result of this change is not only the response of LULC change to the ideal state of the 13th Five-Year Plan on protection the basin, but also the demonstration of the implementation effect of specific policies such as "Four Retreats and Three Returns". This result has greatly increased the forest coverage rate of the basin, and in the core protection area where the pollution source is the most serious, the influence of human activities has been withdrawn, and the ideal state of the natural land types in the core protection area has been realized, forming a natural barrier to the drainage and purification of the lake.

\section{Spatial variation characteristics of LULC}

Using the "per category" module of the MCK image comparison tool, the results of scenario simulation are compared with the actual land use in 2014. The results are as shown in the figure. The types of restricted land types such as cultivated land, forestland, garden land, water area, desert and bare land and construction land are mainly analyzed. In the figure, "in one of the maps" indicates the rest of the land types other than this land type, and "in both maps" indicates areas where there is no change in 2014 and 2017, "only in 2014, not in 2017" indicates a reduced area in 2017 relative to 2014, and "only in 2017, not in 2014" refers to the increased area in 2017 relative to 2014.

Fig. 9 shows that from 2008 to 2017, the cultivated land under the natural change scenario was continuously reduced, mainly converted into forest land, garden land and grassland, and a small part was converted into construction land and desert and bare land; but under the ecological protection scenario, the cultivated land also showed the decreasing trend, but the range was smaller than the natural change scenario. The change of the region has been distributed throughout the basin, and for the areas with higher elevation, the part of the cultivated land also has a decreasing trend.

There is a decreasing trend of forest land under natural changes and ecological protection scenarios. It is mainly concentrated in the high altitude area to the north of Fuxian Lake Basin, and the change of forest land within the ecological protection red line is very small. 

region extent model, Yunnan province, China - 8909 -
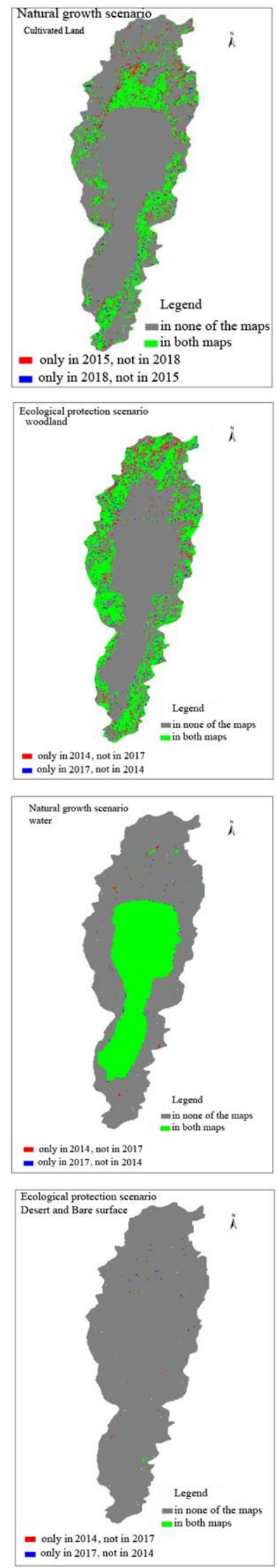
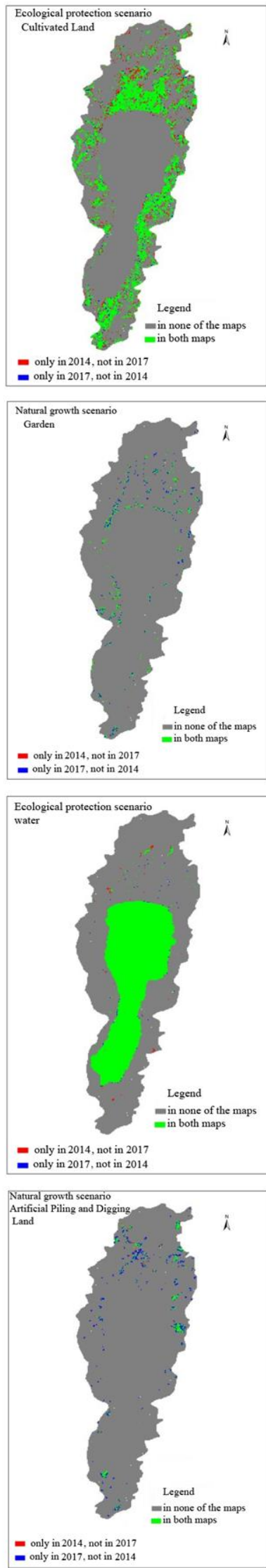
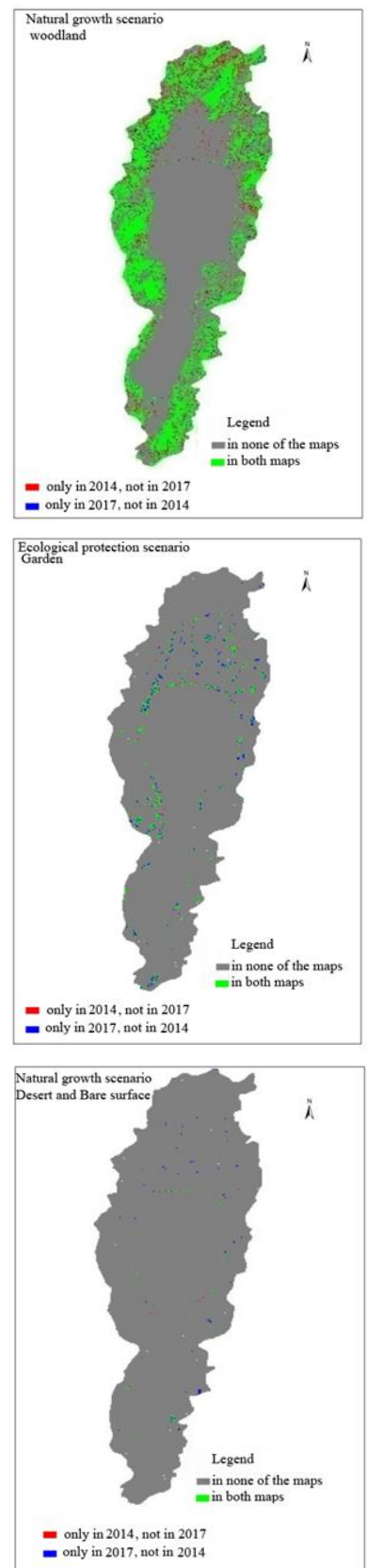

only in 2014, not in 2017
- only in 2017 , not in 2014

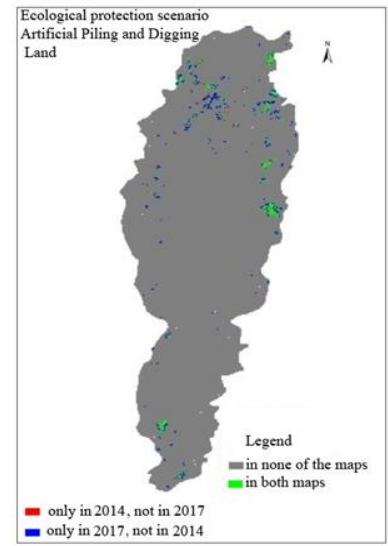

Figure 9. Spatial distribution of LULC types under different scenarios

APPLIED ECOLOGY AND ENVIRONMENTAL RESEARCH 17(4):8895-8914.

http://www.aloki.hu • ISSN 15891623 (Print) • ISSN 17850037 (Online)

DOI: http://dx.doi.org/10.15666/aeer/1704_88958914

(c) 2019, ALÖKI Kft., Budapest, Hungary 
Under the natural change and the ecological protection scenarios, the garden land showed an increasing trend. The garden land area of the natural change scenario increased from 993.28 hectares in 2015 to 1,463.94 hectares, while the ecological protection scenario area increased by $48.68 \%$, which is consistent with the requirements of the ecological protection plan. It is mainly distributed in the middle and low elevation area of the river basin, and in the north and west of the river basin, and it is also the most widely distributed and largest area of the garden land in Chengjiang County.

The distribution of increasing and decreasing water area is close to that of natural change and ecological protection scenarios. The reduced area is the north and northwest of Fuxian Lake Basin, and the waters increase along the edge of the Lake. This fully demonstrates the effectiveness of the policy of returning farmland to lakes and forests in Fuxian Lake Basin.

Under the natural change and ecological protection scenarios, the area of desert, bare land and constructed land all showed an increasing trend. Because the total area of desert, bare land and constructed land is relatively small, but it is an important part of the conversion of ground type, with the highest degree of activity. Although the conversion parameters of the land types are limited in scenario simulation, the general direction of change is unchanged. In the stable change trend, its change area mainly distributes in the urban and rural fringe area with frequent human activities.

\section{Conclusions and Discussion}

\section{Conclusions}

(1) The CLUE-S model has high reliability to simulate the future LULC change in basin scale. The overall simulation accuracy is high, but there are differences in the simulation accuracy of different land types. The simulation accuracy of the garden land, structure, construction land, desert and bare land disturbed by human factors is relatively low, among which the construction land is the lowest. Kappa index of water area and cultivated land are above 0.9 and water area is above 0.99 , which indicates that the driving factors selected in the study could better explain the spatial change of LULC.

(2) Under the natural change scenario, the ecological security of the basin will face serious threats. The forest land, farmland, grassland and garden land is reducing and the decrease of garden land is the largest, while the construction land, building area, structure and road is increasing and the increase of the construction land is the largest. According to the spatial distribution of the change, the cultivated land in the village farmland area decreases obviously, while the impervious surface and other land increase, the forest and grass coverage in the phosphate rock area decreases, and other land increases. However, the impervious surface and other land use in the urban area show an increasing trend, while the cultivated land shows a decreasing trend.

(3) The ecological protection scenario will be beneficial to the ecological environment protection of the river basin. The increase of forestland and water area is the largest, while the cultivated land, grassland, construction land and garden land are greatly reduced. It shows that the quantity of ecological land increases obviously, while the quantity of building land, planting land and other land that restrict the ecological environment protection shows a decreasing trend, which will benefit the ecological environment protection of the river basin. According to the spatial distribution of change, the other lands (desert and bare surface) in the phosphate rock area, the 


$$
\text { - } 8911 \text { - }
$$

construction land in the urban area and the cultivated land in the village farmland area are greatly reduced, while the forest and grass coverage in the three areas show a significant increase trend.

\section{Discussion}

The CLUE-S model is subjective in setting the transition elasticity of land types according to the land use conversion matrix and the land use conversion probability matrix. How to obtain the objective elastic coefficient of land type conversion needs to be further studied. How to couple other models to realize seamless integration of spatial allocation of spatial and non-spatial modules so as to reach the "equilibrium" state of land use change and economic and social development still is not solved. The CLUE-S model needs to be further studied by coupling with other models.

Acknowledgements. The authors are very grateful to the editor and anonymous referees reviews for their valuable comments and helpful suggestions. In addition, this work is supported by National Natural Science Foundation of P.R. China (A coupling effects study of spatial and temporal process between impervious surface area pattern and soil erosion of Dianchi Lake Basin during fast urbanization, Grant no. 41561086; Future land use/cover simulation and its response mechanism to water quality by coupling human activities and climate change effects in Fuxian lake watershed, Grant no. 41861051, Research on cloud resources auto scaling and load balancing by considering the complexity of spatiotemporal computing, Grant no.41661086), and the National Geographical state monitoring demonstrative project -"Dynamic monitoring for ecological environment in Fuxian lake watershed" from National Administration of Surveying, Mapping and Geoinformation (file no. 201435).

\section{REFERENCES}

[1] Bai, W. Q. (2000): Analysis on land use dynamics of Shenzhen. - Journal of Resources 26(2): 112-116.

[2] Bai, W. Q., Zhang, Y. M., Yang, J. Z., Zhang, Y. L. (2005): Simulation of land use dynamics in the upper reaches of the Dadu river. - Geographical Research 24(2): 206-212.

[3] Bian, Z. H., Ma, X. X., Gong, L. C., Zhao, J., Zeng, C. F., Wang, L. C. (2017): Land use prediction based on CLUE-S model under different non-spatial simulation methods: A case study of the Qinhuai river watershed. - Scientia Geographica Sinica 37(2): 252-258.

[4] Cai, Y. M., Liu, Y. S., Yu, Z. R., Verburg, P. H. (2004): Progress in spatial simulation of land use change: CLUE-S model and its application. - Progress in Geography 23(4): 6371.

[5] Chu, D., Zhang, Y. L., Zheng, D. (2005): Land use change scenario in Lhasa district using Markov chain model. - Geographical research 24(6): 869-877.

[6] Dai, S. P., Zhang, B. (2013): Land use change scenarios simulation in the middle reaches of the Heihe river basin based on CLUE-S model-A case of Ganzhou district of Zhangye city. - Journal of Natural Resources 28(2): 336-348.

[7] Deng, H., Shao, J. A., Wang, J. L. (2016): Land use driving forces and its future scenario simulation in the Three Gorges Reservoir Area using CLUE-S model. - Acta Geographica Sinica 71: 1981-1997.

[8] Duan, Z. Q., Verburg, P. H., Zhang, F. R., Yu, Z. R. (2004): Construction of a land-use change simulation model and its application in Haidian district, Beijing. - Acta Geographica Sinica 59(6): 1037-1047.

[9] Feng, S. C., Gao, X. H., Gu, J., Kang, J., Guo, L. F., Wu, G. L., Zou, C. (2013): Land use spatial distribution modeling based on CLUE-S model in the Huangshui River Basin. Acta Ecologica Sinica 33(3): 985-997. 
[10] Gao, H. J., Zhang, C. Q., Wang, H. Z., Luo, X. Q. (2013): Simulation of land use change in Karst mountain area based on CLUE-S model. - Science of Surveying and Mapping 41(2): 76-80.

[11] Gao, W., Chen, Y., Xu, M., Guo, H. C., Xie, Y. C. (2013): Trend and driving factors of water quality change in Lake Fuxian (1980-2011). - Journal of Lake Science 25(5): 635642.

[12] Guo,Y. F., Yu, X. B., Jiang, L. G. (2012): Scenarios analysis of land use change based on CLUE-S model in Jiangxi Province by 2030. - Geographical Research 31(6): 1016-1028.

[13] Guo, H. W., Sun, X. Y., Lian, L. S., Zhang, D. Z., Xu, Y. (2016): Response of water yield function of ecosystem to land use change in Nansi Lake Basin based on CLUE-S model and InVEST model. - Chinese Journal of Applied Ecology 27(9): 2899-2906.

[14] Han, H. R., Yang, C. F., Song, J. P. (2015): Simulation and projection of land-use change in Beijing under different scenarios. - Progress in Geography 34(8): 976-986.

[15] Hou, X. Y., Chang, B., Yu, X. F. (2004): Land use change in Hexi corridor based on CAMarkov methods. - Transactions of the CSAE 20(5): 286-291.

[16] Hu, W., Zhang, B. (2018): Short-term wind power forecast based on back-propagation neural network corrected by Markov chain. - European Journal of Electrical Engineering 20(3): 279-293.

[17] Huang, M., Zhang, X. X., Zhang, J. J., Zhao, Z. Y., Ru, H. (2012): A multi-scale simulation of land use change in Luoyugou watershed based on CLUE-S model. Resources Science 34(4): 769-776.

[18] Huang, S. (2015): Land use spatial simulation in growth mining city. - China University of Geosciences (Beijing): 79.

[19] Jiang, W. G., Chen, Z., Lei, X., Jia, K., Wu, Y. F. (2015): Simulating urban land use change by incorporating an autologistic regression model into a CLUE-S model. Journal of Geographical Sciences 25(7): 836-850.

[20] Li, X. B. (1996): A review of the international researches on land use/land cover change. - Acta Geographica Sinica 51(3): 553-557.

[21] Li, X. C., Diao, H. T., Wang, J., Cui, F. B. (2009): Research progress on forecasting method of regional land use demand in China. - Journal of Shandong Agricultural University (Natural Science) 40(4): 655-658.

[22] Li, S. H., Jin, B. X., Wei, X. Y., Jiang, Y. Y., Wang, J. L. (2015): using ca-markov model to model the spatiotemporal change of land use/cover in fuxian lake for decision support. - Surface Science II-4/W2(5): 163-168.

[23] Li, Y., Huang, S. L. (2016): Hydrological responses to land use change under three future scenarios in Luanhe River Basin. - Chinese Journal of Ecology 35(7): 1970-1980.

[24] Li, W., Xie, D. C., Zhang, J. (2016): Application of landscape ecological method in planning environment impact assessment-a case study for east part of Dalian Forest Park. - China Environmental Science 29(6): 605-610.

[25] Li, B., Liu, Y., Zhang, B. (2017): Multi-scenario land use change simulation in Caidian using CLUE-S based on Tietenberg Modeling. - Resources Science 39(9): 1739-1752.

[26] Li, S. H. (2018): Multi-scale spatiotemporal variation of LULC and its relationship to water quality based on high resolution remote sensing image in Fuxian lake watershed. Phd dissertation, Yunnan Normal university.

[27] Liu, X. P., Li, X., Ai, B., Tao, H. Y., Wu, S. K., Liu, T. (2006): Multi-agent systems for simulating and planning land use development. - Acta Geographica Sinica 61(10): 11011112.

[28] Liu, M., Hu, Y. M., Sun, F. Y. (2012): Application of land use model CLUE-S in the planning of central Liaoning urban agglomerations. - Chinese Journal of Ecology 31(2): 413-420.

[29] Liu, J. H., Li, W. F., Zhou, W. Q., Han, L. J., Qian, Y. G., Zhen, X. X. (2017): Simulation and prediction of changes in the landscape patterns of the Beijing-Tianjin-Hebei metropolitan region and their driving mechanisms. - Acta Ecologica Sinica 37(16): 1-10. 
[30] Liu, X., Liang, X., Li, X., Xu, X., Ou, J., Chen, Y. M., Li, S. Y., Wang, S. J., Pei, F. S. (2017): A future land use simulation model (FLUS) for simulating multiple land use scenarios by coupling human and natural effects. - Landscape \& Urban Planning 168: 94116.

[31] Lu, R. C., Huang, X. J., Zuo, T. H., Xiao, S. S., Zhao, X. F., Zhang, X. Y. (2009): Land use scenarios simulation based on CLUE-S and Markov Composite Model-A case study of Taihu Lake Rim in Jiangsu Province. - Scientia Geographica Sinica 29(4): 577-581.

[32] Lu, W. T., Dai, C., Guo, H. C. (2015): Land use scenario design and simulation based on Dyna-CLUE model in Dianchi Lake Watershed. - Geographical Research 34(9): 16191629.

[33] Meng, J. J., Yan, F., Zhao, C. H. (2010): Land use change simulation on the edge of metropolis-A case study of Changping District in Beijing. - Journal of Basic Science \& Engineering 256(22): 6936-6940.

[34] Peng, J., Cai, Y. L., Verburg, P. H. (2007): Scenario simulation of land use and cover change in Karst Mountainous Areas Based on CLU E-S model. - Journal of Agricultural Engineering 23(7): 64-70.

[35] Peng, P., Cai, Y. L., Verburg, P. H. (2007): Simulation of land use/cover change scenarios in Karst mountain areas. - Transactions of the Chinese Society of Agricultural Engineering 23(7): 64-70.

[36] Qin, X. H., Duan, X. J., Li, H., Lu, Y. T. (2009): Urban land expansion simulationm ODEL based on SD and CA- A case study of Nantong city. - Scientia Geographical Sinica 29(3): 439-444.

[37] Sheng, S., Liu, M. S., Xu, C. (2008): Application of CLUE-S model in simulating land use changes in Nanjing metropolitan region. - Chinese Journal of Ecology 27(2): 235239.

[38] Sun, L. N., Liang, D. M. (2016): Effect of future land use change on hydrology in Dongliaohe basin. - Research of Soil and Water Conservation 23(5): 164-168.

[39] Tan, Y. Z., Wu, C. F., Mu, Y. M., Wang, Q. R., Yu, Z. G. (2006): Simulation of land use spatial pattern change on county scale in the rapid economic development region. Transactions of the Chinese Society of Agricultural Engineering 22(12): 72-77.

[40] Tian, T. Y., Li, B. S. (2019): Optimization and Simulation of Urban Land Use Pattern Based on the Perspective of Objective Constraint: A Case of Hohhot. - Chinese Agricultural Science Bulletin 35(9): 86-94.

[41] Verburg, P. H., Soepboer, W., Veldkamp, A., Limpiada, R., Espaldon, V., Mastura, S. S. A. (2002): Modeling the spatial dynamics of regional land use: the CLUE-S model. Environmental Management 30(3): 391-405.

[42] Verburg, P. H., Overmars, K. P. (2009): Combining top-down and bottom-up dynamics in land use modeling: Exploring the future of abandoned farmlands in Europe with the Dyna-CLUE model. - Landscape ecology 24(9): 1167-1181.

[43] Wang, S. M., Dou, H. S. (1998): The annals of Chinese Lake. - Beijing: Science Press 374-377.

[44] Wang, J., Tian, G., Quan, Q., Jiang, J. (2009): Dynamic simulation of land use pattern in Guangzhou based on CLUE-S model. - Chinese Journal of Ecology 29(6): 1257-1262.

[45] Wang, Q., Meng, J. J., Mao, X. Y. (2014): Scenario simulation and landscape pattern assessment of land use change based on neighborhood analysis and auto-logistic model: A case study of Lijiang River Basin. - Geographical Research 33(6): 1073-1084.

[46] Wang, X., Liu, W. L., Zhang, L., Zheng, J. (2014): Landscape Spatial Distribution Modeling Based on CLUE-S Model in the Liaohe Watershed. - Journal of GeoInformation Science 16(6): 925-932.

[47] Wang, B. S., Liao, J. F., Zhu, W., Qiu, Q. Y., Wang, L., Tang, L. N. (2019): The weight of neighborhood setting of the FLUS model based on a historical scenario: A case study 
of land use simulation of urban agglomeration of the Golden Triangle of Southern Fujian in 2030. - Acta Ecologica Sinica 39(12): 1-15.

[48] Wijesekara, G. N., Gupta, A., Valeo, C. (2012): Assessing the impact of future land-use changes on hydrological processes in the Elbow River watershed in southern Alberta, Canada. - Journal of Hydrology 412/413: 220-232.

[49] Xu, X. L., Li, X., Xiao, C. J., Ou, M. (2016): Land use layout optimization under different scenarios by using the CLUE-S model. - Acta Ecologica Sinica 36(17): 54015410.

[50] Zhang, Y. M., Zhao, S. D., Verburg, P. H. (2004): Scenario analysis of land use change in Horqin Desert and its surrounding area. - Journal of Natural Resources 19(1): 29-37.

[51] Zhang, L. J., Li, W. L., Liu, D., Zhou, D. Y., Verburg, P. H. (2011): Dynamic simulation of the spatial changes of land use in the Ha-Da-Qi Industrial Corridor. - Progress in Geography 30(9): 1180-1186.

[52] Zhang, D. X., Fu, M. C., Tao, J., Hu, L. Z., Yang, X. L. (2013): Scenario simulation of land use change in mining city based on CLUE-S model. - Transactions of the Chinese Society of Agricultural Engineering 29(12): 246-256.

[53] Zhao, G. L., Hu, Y. C. (2014): Study on ecosystem service value changes based on CLUE-S models in Guangxi karst mountainous area. - Research of Soil and Water Conservation 21: 198-203.

[54] Zheng, W. H., Shen, Q. P., Wang, H., Hong, J. K. (2014): Simulating land use change in urban renewal areas: A case study in Hong Kong. - Habitat International 46: 23-34.

[55] Zhou, R., Su, H. L., Wang, X. J., Li, Y. H., Hu, Y. M. (2016): Simulation and accuracy assessment of village land use change based on CLUE-S model. - Resources and Environment in the Yangtze Basin 21(2): 174-180.

[56] Zhou, Z., Tian, N., Zhao, Y. H. (2017): Prediction and Analysis of the Age Population Scale of Compulsory Education in Tianjin based on multi-factor grey prediction model and population estimation algorithm. - Journal of Xinan Normal University (Natural Science) 42(3): 49-55.

[57] Zhu, Z. Q., Liu L. M., Chen, Z. T., Zhang, J. L., Verburg, P. H. (2010): Land-use change simulation and assessment of driving factors in the loess hilly region: A case study as Pengyang county. - Environmental Monitoring and Assessment 164(1-4): 133-142.

[58] Zhu, W. B., Zhang, J. J., Cui, Y. P. (2019): Assessment of territorial ecosystem carbon storage based on land use change scenario: A case study in Qihe River Basin. - Acta Geographica Sinica 74(3): 446-459. 